\title{
Disruption of sexual function, FSH secretion, and spermiogenesis in rabbits following developmental exposure to vinclozolin, a fungicide
}

\author{
D N R Veeramachaneni, J S Palmer, R P Amann, C M Kane, T T Higuchi and K-Y F Pau ${ }^{1}$ \\ Animal Reproduction and Biotechnology Laboratory, Colorado State University, Fort Collins, CO 80523-1683, \\ USA and ${ }^{1}$ Division of Reproductive Science, Oregon National Primate Research Center, Beaverton, Oregon, USA
}

Correspondence should be addressed to DNR Veeramachaneni; Email: D_N_Rao.Veeramachaneni@colostate.edu

K-Y F Pau is now at PrimeGen Biotech, 213 Technology Drive, Irvine, CA 92618, USA

\begin{abstract}
We studied sequelae of prenatal plus infantile exposure of male rabbits to vinclozolin, because it is ingested by women and children. Female Dutch-Belted rabbits (7-10/group) were treated daily per orum from gestation day 15 through post-natal week 4 to provide $0,7.2$, or $72 \mathrm{mg}$ vinclozolin $/ \mathrm{kg}$ dam's body weight/day. Vinclozolin had no effect on maintenance of pregnancy, growth of pups, age at testicular descent or weight of organs. Concentrations of serum LH or testosterone at 6, 12, or 24 weeks of age were unaffected. However, FSH was lower $(P<0.05)$ in both vinclozolin groups at all three ages. Following injection of $\mathrm{GnRH}$ at 12 or 24 weeks, the increase in FSH was less $(P<0.05)$ in both vinclozolin groups, as was testosterone at 12 weeks of age. After full sexual maturity, 2 of 7 low dose rabbits were uninterested in female or male teasers and never achieved erection or ejaculation. Overall, rates of ejaculation failure were: control $0 \%(0 / 48)$, low dose $29 \%(12 / 42)$, and high dose $5 \%(3 / 60)$. Daily sperm production per gram of testis and total number of sperm per ejaculate in both vinclozolin groups were similar $(P>0.1)$ to controls. However, semen from vinclozolin rabbits contained over two times more $(P<0.05)$ morphologically abnormal spermatozoa, mostly nuclear and acrosomal defects, than semen from controls. Seminiferous tubules with degenerative changes were more frequent $(P<0.05)$ in vinclozolin rabbits than in controls. Lesions included syncytia of spherical spermatids and desquamation of germ cells. Hence, developmental exposure to vinclozolin caused presumably permanent changes in copulatory ability, secretion of FSH, and spermiogenesis.

Reproduction (2006) 131 805-816
\end{abstract}

\section{Introduction}

Vinclozolin (3-(3,5-dichlorophenyl)-5methyl-5-vinyl-oxazolidine-2,4-dione) is a systemic dicarboximide fungicide used on plants, fruits, vegetables and turf grass - certain uses now withdrawn in the USA. The potential problem is that hydrolytic products 2-[[(3,5-dichlorophenyl)-carbamoyl]oxy]-2-methyl-3-butenoic acid (M1) and especially 3',5'-dichloro-2-hydroxy-2-methylbut-3-enanilide (M2) effectively compete with endogenous androgens for androgen receptor ( $K_{\mathrm{i}}$ vs R1181 (methyltrienolone) of more than 700, 92 and $9.7 \mu \mathrm{M}$ for vinclozolin, M1 and M2; Kelce et al. 1994), and block the desired response. Both M1 and M2 are formed in rats and rabbits (Kelce et al. 1994, Moorman et al. 2000), and accumulate in soil, plants, and animals. There is a paucity of information on human exposure to metabolites of vinclozolin. Based on rat data, a chronic no-observed-adverse-effect level (NOAEL) for vinclozolin of $1.2 \mathrm{mg} / \mathrm{kg} /$ day has been established for humans
(NTP/NIEHS 2001), in recognition of potential for impact on reproductive development.

Aberrations in differentiation and development of male reproductive system including cryptorchidism and hypospadias have become a major concern. Some attributed the problem to maternal exposure to environmental estrogenic or anti-androgenic agents (Toppari et al. 1996, Skakkebaek et al. 2001). Sexual dysfunction also is recognized as an important public health concern (Laumann et al. 1999), and has been linked to environmental pollutants (Oliva et al. 2002). Vinclozolin might be one such anti-androgenic environmental agent. Perinatal exposure of rats to vinclozolin impairs reproductive development. For example, rats exposed during fetal and neonatal development (100 mg vinclozolin/kg mother's body weight/day from gestational day (GD) 14 through postnatal day (PND) 3) manifested hypospadias, cleft phallus, and cryptorchidism (Gray et al. 1994).

Exposure to environmental anti-androgenic agents during critical periods in fetal development can alter the 
organization or differentiation of the neuroendocrine system, and subsequent sexual function and behavior (reviewed by Gray et al. 2001). Indeed, exposure of Sprague-Dawley rats on PND 2 and 3 to $200 \mathrm{mg}$ vinclozolin/kg reduced play behavior of male rats at PND 36-37 to a level characteristic of females; play behavior in rats is sexually dimorphic (Hotchkiss et al. 2003). Strain, dose and age at exposure to vinclozolin might be important, because Long-Evans rats exposed daily to $12 \mathrm{mg}$ vinclozolin/kg body weight/day from GD 14 to PND 3 had significantly increased play behavior on PND 34 , and significantly reduced number of erections as adults (Colbert et al. 2005).

It is not known if pre-natal exposure of rats or nonrodent animal models to relatively low doses of vinclozolin impairs sexual function and spermatogenesis when adult, as is suspected for humans. In the 1993 report Pesticides in the Diets of Infants and Children, prepared by the National Research Council, serious concern was expressed that the young are at special risk with respect to pesticide exposures. They urged that 'testing must be performed during the developmental period in appropriate animal models' (NRC 1993).

We selected a rabbit model primarily because rabbits have a long infantile period before initiation of changes culminating in puberty, mimicking human development, whereas in rodents these changes start at birth (Amann 1982, Veeramachaneni et al. 2001). Also, perinatal developmental events are well documented for the rabbit (Bloch et al. 1971, Gondos et al. 1973, 1975, Bjerregaard et al. 1974, Gondos 1974, Catt et al. 1975). Furthermore, use of rabbits (in contrast to rodents) facilitates multiple evaluations of seminal quality and sexual capacity. Herein, we report reproductive sequelae, measured before puberty and also after sexual maturity, in rabbits following prenatal plus infantile exposure to vinclozolin.

\section{Materials and Methods}

\section{Animals}

Six-month-old, specific-pathogen-free, Dutch-Belted rabbits were obtained from Covance Research Products Inc (Denver, PA, USA) and individually housed in standard stainless steel cages in the university animal care facility accredited by the Association for Assessment and Accreditation of Laboratory Animal Care, International. Protocols met standards of Colorado State University's institutional Animal Care and Use Committee. The room maintained a $12 \mathrm{~h}$ light-darkness cycle, at $19-21^{\circ} \mathrm{C}$ and $\sim 40 \%$ humidity. Rabbits were fed certified rabbit ration ( $\# 7015 \mathrm{C}$, Harlan, Teklad, Madison, WI, USA) and were provided water ad libitum.

After acclimatization for 3-4 weeks, virgin rabbit does were artificially inseminated with $20 \times 10^{6}$ spermatozoa, pooled from semen collected from 6 bucks using standard procedures (Veeramachaneni et al. 2001). Rabbits were palpated for pregnancy 14 days after insemination and 6-7 pregnant rabbits were randomly assigned to each treatment group (see below). On PND 21, female pups were culled and on PND 42, male pups were weaned and caged individually. Body weights were recorded at 6,12 , and 24 weeks of age.

\section{Dosing regimen and experimental design}

Vinclozolin (CAS \# 50471-44-8, catalog\# PS-1049, lot \# 209-40B; 99.8\% pure; molecular weight 287; Chem Service, Inc., West Chester, PA, USA) was administered orally as a homogeneous suspension in a $1 \mathrm{ml}$ mixture of deionized water:Karo Light Corn Syrup (50:50) (Best Foods, Englewood Cliffs, NJ, USA). Rabbit does were dosed with 0 (vehicle only control; $n=6$ ), $7.2 \mathrm{mg}$ ( $25 \mu \mathrm{mol}$, low dose; $n=7)$ or $72 \mathrm{mg}(250 \mu \mathrm{mol}$, high dose; $n=7$ ) vinclozolin/ $\mathrm{kg} /$ day from GD 15 to postpartum week 4 (PND 28), in consideration of an acute NOAEL of $6 \mathrm{mg} / \mathrm{kg} /$ day (US EPA 2000). In utero exposure was begun on GD 15 to ensure that major organogenesis was completed before the start of the treatment and dosing was stopped at PND 28 when pups typically stop nursing. This window of exposure corresponds with the onset of gonadal differentiation (Gondos et al. 1973) and development of the male reproductive tract.

Tissue or serum concentrations of vinclozolin or its metabolites were not measured and, hence, the amount of vinclozolin-like molecules transferred to fetuses or nursing pups during in utero and lactational exposure is unknown. It is presumed that their collective concentration was lower than the dosed amount.

At weaning ( 6 weeks), there were 15 control male pups (representing 6 litters), 14 low dose (7 litters), and 20 high dose (7 litters) vinclozolin-exposed male pups. Based on a random draw, 7, 7, and 10 pups from the respective groups were assigned to be killed at 12 weeks (before puberty) and the remaining to be killed at 24 wk (sexually mature), yet ensuring that the 24 weeks group included at least one pup from each litter.

\section{Blood sampling and hormone measurements}

Blood $(4-5 \mathrm{ml})$ was taken by jugular puncture from all males at 6 weeks of age and from males in the respective groups at 12 or 24 weeks. Serum concentrations of follicle-stimulating hormone ( $\mathrm{FSH})$, luteinizing hormone (LH) and testosterone were determined. Status of the anterior pituitary-testicular axis and its capability to respond to hypothalamic stimuli were assessed at 12 and 24 wk by performing gonadotropin-releasing hormone $(\mathrm{GnRH})$-challenge tests. After taking the aforementioned baseline blood sample, $10 \mu \mathrm{g}$ GnRH were injected intramuscularly, and two more blood samples were collected 30 and $120 \mathrm{~min}$ later. Serum was separated, and stored at $-20^{\circ} \mathrm{C}$. Concentrations of $\mathrm{FSH}$ and $\mathrm{LH}$ were determined by validated radioimmunoassays (Pau et al. 1986) using 
homologous rabbit reagents provided by Dr A Parlow and the Pituitary Hormone Program, National Institutes of Health. The final dilutions of antisera for FSH and $\mathrm{LH}$ were 1:72000 and 1:2160000, respectively. Also, an aliquot of each sample was extracted and assayed for testosterone using a validated radioimmunoassay (Berndtson et al. 1974). For a given hormone, all samples were assayed concurrently and intra-assay coefficients of variation were $11 \%$ for $\mathrm{FSH}, 5 \%$ for $\mathrm{LH}$ and $4 \%$ for testosterone.

\section{Evaluation of mating ability and semen characteristics}

Beginning at 20 weeks of age, rabbits were trained for semen collection using an artificial vagina and a female rabbit as a teaser. Every third day for 2 weeks, one of the several receptive female teasers was introduced into the cage of a male, and the male was allowed to mount and intromit the artificial vagina held under the rear end of the teaser.

The artificial vagina was simplified from Bredderman et al. (1964). A $2 \mathrm{~cm}$ diameter Tygon tube (B44-4x, Fisher Scientific, Fair Lawn, NJ, USA) was cut into $4.5 \mathrm{~cm}$ long pieces. A $7.5 \mathrm{~cm}$ long piece of $2 \mathrm{~cm}$ diameter Penrose surgical drain latex tube (MWI Veterinary Supply, Nampa, ID, USA) was inserted into the Tygon tube as inner liner and a $0.6 \mathrm{~cm}$ end-portion was folded over the Tygon tube. The space between the Tygon tube and the inner liner was filled with tap water and then the other end of inner liner was folded over the Tygon tube. Both ends of the foldedover inner liner were secured to the Tygon tube with rubber bands. Collection vials $(4.5 \mathrm{ml}$ capacity) were prepared by cutting off the bottom $5 \mathrm{~cm}$ of a $15 \mathrm{ml}$ conical, graduated polycarbonate centrifuge tube. At least $2 \mathrm{~h}$ before use, artificial vaginas were placed into an incubator at $50^{\circ} \mathrm{C}$. Just prior to use, a collection vial was inserted into one end of an artificial vagina and a small amount of glycerol was smeared on the opening into the artificial vagina (end that comes into contact with penis).

Between 22 and 24 weeks of age, mating ability and semen characteristics were evaluated by attempting to collect six seminal ejaculates from each rabbit; one ejaculate every third day. One of several female teasers was selected randomly for each attempt at semen collection. When a male showed no sexual interest in a female teaser, a male teaser was introduced. Testing with a male teaser (as in third clip in the video; see below in Results section) was initiated because in another study, investigating long-term sequelae of developmental exposure to common chemical pollutants in drinking water, we found that some treated males preferred male to female teasers (Veeramachaneni et al. 2001).

For each episode, mating ability was subjectively evaluated by monitoring the outcome and recording: 1) sexual interest; 2) status of penile erection; 3) number of mounts to accomplish ejaculation; and 4) time from introduction of teaser to ejaculation (reaction time). Once the teaser was introduced, evaluation continued until ejaculation or a maximum period of $180 \mathrm{~s}$. Male rabbits evince sexual interest by sniffing the hind quarters and external genitalia of the teaser and mounting. Failure to manifest such behavior was considered lack of sexual interest. As the male mounts and positions himself for penile intromission, the operator holding the artificial vagina (under the posterior abdominal aspect of the teaser) can feel and assess the erectile status of the penis prior to intromission and ejaculation. As the male intromits and ejaculates, he grasps the nape of the teaser with his teeth. Upon completion of ejaculation, it is not unusual for the male to pull hair from the nape of the teaser as he dismounts.

For each sample, seminal volume (after removing the gel) was recorded (to the nearest $0.05 \mathrm{ml}$ ), semen was mixed, and a $50 \mu \mathrm{l}$ aliquant of semen was fixed in $950 \mu \mathrm{l}$ phosphate-buffered formal saline $(93 \mathrm{mM} \mathrm{NaCl}, 35 \mathrm{mM}$ $\mathrm{Na}_{2} \mathrm{HPO}_{4}, 19 \mathrm{mM} \mathrm{KH} \mathrm{PO}_{4} ; 12.5 \%$ v/v formalin; Hancock 1957) and stored at $4{ }^{\circ} \mathrm{C}$ until evaluation. Sperm concentration $\left(10^{6} / \mathrm{ml}\right)$ was determined by hemocytometer (4 chambers/sample) and total sperm per ejaculate $\left(10^{6}\right)$ calculated by multiplying volume times sperm concentration. Morphological features of sperm were evaluated in a treatment-blinded manner using a light microscope equipped with differential interference contrast optics. Two hundred sperm/ejaculate were evaluated in wet smears for abnormalities of the acrosome, head, mid- and principal pieces, retention of cytoplasmic droplet, and presence of residual cytoplasm using criteria previously established for rabbits (Veeramachaneni et al. 2001).

\section{Tissue sampling and preparation}

Rabbits were euthanized by $\mathrm{CO}_{2}$ asphyxiation at 12 or 24 weeks of age. Liver, kidneys, testes, epididymides, and accessory sex glands (prostate, vesicular and bulbourethral glands) were evaluated for any gross abnormalities, removed, and weighed. Testes and epididymides were weighed individually. Left testis and epididymis were processed for light and transmission electron microscopy (Veeramachaneni et al. 1986, 1993). The testis was sliced into two pieces; one piece was fixed in Bouin's fixative (Picric acid $750 \mathrm{ml}$ (saturated aqueous solution), glacial acetic acid $25 \mathrm{ml}, 37 \%$ formalin $250 \mathrm{ml}$ ) and the other in $4 \%(\mathrm{v} / \mathrm{v})$ glutaraldehyde in $0.1 \mathrm{M}$ sodium cacodylate. The epididymis was fixed in Bouin's fluid. Tissues fixed in Bouin's fluid were embedded in paraffin and those fixed in glutaraldehyde were post-fixed in osmium tetroxide and embedded in Poly/Bed 812 (Polysciences, Warrington, PA, USA). Thick sections $(5 \mu \mathrm{m})$ were cut from paraffinembedded tissues and stained with hematoxylin and eosin (light microscopy) and thin sections $(60-80 \mathrm{~nm})$ were cut from Poly/Bed-embedded tissues and stained with uranyl acetate and lead citrate (transmission electron microscopy).

The right testis and epididymis were processed to allow quantification of daily sperm production and epididymal 
sperm reserves. The epididymis was dissected from the testis, cut into two segments (caput-corpus, cauda), weighed, frozen and stored at $-80^{\circ} \mathrm{C}$. The testis was decapsulated, weighed, frozen and stored at $-80^{\circ} \mathrm{C}$.

\section{Daily sperm production and epididymal sperm reserves}

Daily sperm production and epididymal sperm reserves were determined by procedures described for rabbits (Amann \& Lambiase 1969) with minor modifications. Briefly, testicular parenchyma was thawed, minced on a watch glass, and homogenized for $1 \mathrm{~min}$ in a semi-micro Waring blender using $50 \mathrm{ml}$ buffer $(0.145 \mathrm{M} \mathrm{NaCl}$ containing $4 \mathrm{mM} \mathrm{NaN}_{3}$ and $0.05 \%$ (v/v) TritonX-100). The number of homogenization-resistant elongated spermatid nuclei was determined without further dilution using a hemocytometer (4 chambers/sample). Daily sperm production was calculated using a time divisor of 5.35 days (Amann et al. 1974) and expressed per gram of testicular parenchyma. A caput-corpus or cauda epididymidis was thawed, minced on a watch glass, and homogenized for $3 \mathrm{~min}$ using 50 or $125 \mathrm{ml}$ of buffer, respectively. Without further dilution, sperm nuclei were counted using a hemocytometer (4 chambers/sample). Epididymal sperm reserve was expressed per epididymal segment.

\section{Histopathology of the testis}

Seminiferous epithelium and interstitium were evaluated using a Nikon Microphot-FXA light microscope and a JEOL-1200EX transmission electron microscope. For light microscopy, 100 randomly selected, essentially round (major diameter less than $1.5 \times$ minor diameter) cross sections of seminiferous tubules from each animal were classified into one of eight different grades indicating relative severity of seminiferous epithelial abnormalities (Veeramachaneni et al. 1986, Higuchi et al. 2003). Briefly, grade 0 - normal intact seminiferous epithelium; grade 1 - seminiferous epithelium with pyknotic germ cells and desquamation or focal vacuolation; grade 2 - seminiferous epithelium intermediate between grades 1 and 3; grade 3 - seminiferous epithelium with pre-meiotic germ cells and Sertoli cells; grade 4 - Sertoli cells only; grade 5 - no seminiferous epithelium leaving only the basement membrane; grade 6 - seminiferous tubule with sperm stasis, sperm granuloma, or mineralization; grade 7 - fibrosis of the seminiferous tubule. A weight between 0 and 1 , to reflect relative absence of germ cells, was assigned to each grade $-0,1 / 4,2 / 4,3 / 4$ to grades $0,1,2,3$, respectively, and $4 / 4$ to grades 4 through 7 . The degree of germinal epithelial loss (DGEL) was calculated by multiplying the percentage of tubules in each grade by the respective assigned weight and summing products. For electron microscopy, corresponding tissue sections were evaluated for any subtle lesions or abnormal cells.

\section{Statistical analyses}

Data for each attribute, at each age, were subjected to analysis of variance (Statview, version 5.0, SAS Institute Inc., Cary, NC, USA). We considered the male as the experimental unit, because for the majority of does we studied only 1 pup of a given age from her litter. Effects of low and high dose vinclozolin treatments were compared against the control using Tukey-Kramer post-hoc test with $\alpha \leq 0.05$. This model was used to evaluate body weights, hormone concentrations, and necropsy data. Percentage values were transformed using arcsine of the square root of the percentage/100 to minimize inequality in variance.

\section{Results}

There was no adverse effect of vinclozolin treatment on maintenance of pregnancy to full term. Vinclozolin at these dose levels did not interfere with testicular descent or affect growth of pups as reflected by body weights of vinclozolin-exposed rabbits at 6 weeks of age compared with controls (low dose: $887 \mathrm{~g}$, high dose: $833 \mathrm{~g}$, vs control: 834 g; pooled S.E.M. 25 g; $P>0.1$ ). At 12 or 24 weeks of age, weights of body, kidneys, left testis, left epididymis, or accessory sex glands of vinclozolin-exposed rabbits were not different from those of controls (Table 1). Weight of liver in 24 week old low-vinclozolin males was lower than that in controls $(P<0.05)$.

Table 1 Organ weights at necropsy in 12- and 24-week-old rabbits developmentally exposed to vinclozolin.

\begin{tabular}{|c|c|c|c|c|c|c|}
\hline \multirow[b]{2}{*}{ Organ Weight (g) } & \multicolumn{3}{|c|}{12 weeks } & \multicolumn{3}{|c|}{24 weeks } \\
\hline & Control & Low vinclozolin & High vinclozolin & Control & Low vinclozolin & High vinclozolin \\
\hline$n$ & 7 & 7 & 10 & 8 & 7 & 10 \\
\hline Body & $1574 \pm 50$ & NA & $1549 \pm 71(4)$ & $2105 \pm 55$ & $1958 \pm 26$ & $2153 \pm 33(9)$ \\
\hline Testis & $0.75 \pm 0.07$ & $0.65 \pm 0.45$ & $0.78 \pm 0.04$ & $1.91 \pm 0.12$ & $1.94 \pm 0.09$ & $1.86 \pm 0.10$ \\
\hline Epididymis & $0.34 \pm 0.03$ & $0.30 \pm 0.14$ & $0.32 \pm 0.02$ & $0.73 \pm 0.05$ & $0.67 \pm 0.04$ & $0.65 \pm 0.02$ \\
\hline Accessory Sex Glands & $1.09 \pm 0.11$ & $1.13 \pm 0.08$ & $0.97 \pm 0.06$ & $3.70 \pm 0.41$ & $2.93 \pm 0.33$ & $2.89 \pm 0.20$ \\
\hline Liver & $57.1 \pm 3.6$ & $57.9 \pm 2.4$ & $57.4 \pm 3.3$ & $68.9 \pm 3.9$ & $54.3 \pm 2.2 *$ & $68.4 \pm 3.1$ \\
\hline Paired Kidneys & $12.3 \pm 0.4$ & $12.3 \pm 0.6$ & $12.4 \pm 0.5$ & $13.4 \pm 0.2$ & $12.3 \pm 0.4$ & $13.7 \pm 0.3$ \\
\hline
\end{tabular}

Values are mean \pm S.E.M.; Numbers in parenthesis indicate number of animals for which data are available; weights of left testis and epididymis are presented; NA; not available. Within a row in an age group, values with an asterisk are different from control $(P<0.05)$ with ANOVA and Tukey-Kramer posthoc test. 


\section{Sexual behavior and mating ability}

Sexual behavior and mating capability of certain rabbits were abnormal 20 weeks after cessation of exposure to vinclozolin (Table 2). On a per attempt basis, low dose vinclozolin rabbits failed to accomplish ejaculation in $29 \%$ of episodes (12/42), whereas high dose rabbits failed in $5 \%$ of attempts (3/60), and control rabbits failed in $0 \%$ of attempts (0/48). Two (from the same litter) of 7 low-dose rabbits failed in each of 6 episodes to achieve erection or accomplish ejaculation, within the $180 \mathrm{~s}$ observation period, when presented with a female or male teaser. That these two rabbits were sexually mature was evidenced by testis weight, daily sperm production per gram testis, and presence of a full complement of spermatogenesis in testicular sections. Serum concentrations of $\mathrm{FSH}, \mathrm{LH}$ and testosterone in these two rabbits were not substantially different from values for others in the group.

Excluding the 2 rabbits that evinced no sexual interest or penile erection, 5 low dose males required $2-3$ mounts in 7 of 30 episodes (23\%); 2 of 10 high dose males failed in 1-2 episodes and collectively high dose males required $2-3$ mounts in 9 of 57 other episodes (16\%); and control males never failed and required $2-3$ attempts in 8 of 48 episodes $(17 \%)$. Excluding episodes that did not result in ejaculation, time to ejaculation was less than $30 \mathrm{~s}$ in 27 of 30 episodes (90\%) for low dose males, 45 of 57 episodes $(79 \%)$ for high dose males, and 37 of 48 (77\%) episodes for control males. Mean reaction times for low dose, high dose, and control males were $17.3 \pm 2.5,23.4 \pm 4.3$, and $19.1 \pm 1.8 \mathrm{~s}$. Thus, 2 of 7 low-dose vinclozolin rabbits were aberrant in respect to erectile function and desire to copulate (playful; showed no interest to mount).

Video documentation of sexual behavior/activity (or lack there of) in male rabbits exposed to low dose vinclozolin during early development can be found in Supplementary Data at: http://www.reproduction-online.org/supplemen$\mathrm{tal} /$. There are three sequences in the video - the first shows a control male rabbit (blue spotlight) accomplishing ejaculation with a female teaser (pink spotlight) in $9 \mathrm{~s}$; the others show complete lack of sexual interest and playful behavior of a low dose vinclozolin rabbit with a female (second clip) or a male (third clip) teaser. Crawl-over or frolicking hops usually are seen among nursing littermates, prior to individual caging at PND 42, and are typical of infantile/adolescent social behavior.

\section{Hypothalamo-pituitary-testicular axis}

At 6 weeks of age, average concentrations of $\mathrm{LH}$ and testosterone were similar for all groups $(0.3-0.8$ and $3.1-4.8 \mathrm{ng} / \mathrm{ml}$; data not shown), although the average $\mathrm{LH}$ concentration for the high vinclozolin group was higher $(P<0.05)$ than that for the control group. However, FSH was low in both vinclozolin groups (means \pm S.E.M.: low $15.13 \pm 1.65$, high $16.11 \pm 0.67$ vs control $75.35 \pm 8.05 \mathrm{ng} / \mathrm{ml} ; P<0.05)$. At 12 or 24 weeks of age, baseline serum concentrations of $\mathrm{LH}$ or testosterone for either vinclozolin dose group did not differ $(P>0.1)$ from those of respective controls (Table 3). However, at both ages basal serum concentrations of FSH were lower $(P<0.05)$ in both vinclozolin groups.

At both 12 and 24 weeks of age, injection of $\mathrm{GnRH}$ evoked a substantial discharge of $\mathrm{LH}$ as evidenced $30 \mathrm{~min}$ later (Table 3). The magnitude of the increase in serum LH was similar in vinclozolin-exposed animals and controls. By 120 min post-GnRH, LH concentration was not different from the pre-GnRH level, except in 12 week-old low vinclozolin rabbits in which it was higher $(P<0.05)$ than controls. Secretion of testosterone increased in response to the $\mathrm{LH}$ discharged after $\mathrm{GnRH}$ injection in all 3 groups at both ages. However, compared with controls, the magnitudes of this increase were lower $(P<0.05)$ at 30 or $120 \mathrm{~min}$ in both vinclozolin groups at 12 weeks of age, but only for $120 \mathrm{~min}$ at 24 weeks of age. Injection of $\mathrm{GnRH}$ also evoked secretion of $\mathrm{FSH}$ for males in all 3 groups (Table 3). However, the magnitude of the increase in FSH was lower $(P<0.05)$ in both vinclozolin groups than in the control group at both 30 and 120 min, regardless of age.

\section{Spermatogenesis: quantity and quality}

Developmental exposure to vinclozolin at the dose levels tested did not affect number of sperm produced $\sim 5$ months later, but clearly impaired spermiogenesis resulting in morphologically defective sperm (Table 4). Daily sperm production per gram of testis, sperm reserves in the epididymis, and total number of sperm per ejaculate for vinclozolin-exposed rabbits were not different $(P>0.1)$ from those of controls. However, percentage of morphologically normal spermatozoa, as evaluated by differential interference contrast microscopy, was reduced by one-

Table 2 Sexual behavior and mating ability at 22-24 weeks-of age for rabbits developmentally exposed to vinclozolin.

\begin{tabular}{|c|c|c|c|c|c|c|c|}
\hline \multirow[b]{2}{*}{ Treatment } & \multirow[b]{2}{*}{$n$} & \multirow{2}{*}{$\begin{array}{l}\text { No. of males never } \\
\text { evinced sexual interest, } \\
\text { achieved erection or } \\
\text { ejaculation }\end{array}$} & \multirow{2}{*}{$\begin{array}{c}\text { No. of males } \\
\text { evinced no sexual } \\
\text { interest at least } \\
\text { once }\end{array}$} & \multirow{2}{*}{$\begin{array}{l}\text { No. of males } \\
\text { failed to ejaculate } \\
\text { at least once }\end{array}$} & \multirow{2}{*}{$\begin{array}{l}\text { No. of males with } \\
\text { azoospermic } \\
\text { ejaculation } \\
\text { at least once }\end{array}$} & \multicolumn{2}{|c|}{$\begin{array}{l}\text { Time to } \\
\text { ejaculation (s)* }\end{array}$} \\
\hline & & & & & & mean \pm S.E.M. & range \\
\hline Control & 8 & 0 & 0 & 0 & 0 & $19.10 \pm 1.83$ & $5-52$ \\
\hline Low vinclozolin & 7 & 2 & 2 & 2 & 0 & $17.30 \pm 2.52(30)$ & $6-74$ \\
\hline High vinclozolin & 10 & 0 & 2 & 2 & 1 & $23.36 \pm 4.36(56)$ & $5-180$ \\
\hline
\end{tabular}

*Excludes time for occasions which culminated in failure to ejaculate; numbers in parentheses are total number of ejaculates collected. 
Table 3 Reproductive hormones in 12- and 24-week-old male rabbits developmentally exposed to vinclozolin.

\begin{tabular}{|c|c|c|c|c|c|c|}
\hline & \multicolumn{3}{|c|}{12 weeks } & \multicolumn{3}{|c|}{24 weeks } \\
\hline & Control & Low vinclozolin & High vinclozolin & Control & Low vinclozolin & High vinclozolin \\
\hline$n$ & 6 & 7 & 10 & 5 & 7 & 10 \\
\hline \multicolumn{7}{|l|}{ Serum FSH (ng/ml) } \\
\hline Pre-GnRH & $89.3 \pm 16.8$ & $19.0 \pm 2.6 *$ & $16.4 \pm 1.5^{*}$ & $70.7 \pm 34.4$ & $10.8 \pm 2.0 *$ & $12.7 \pm 1.6 *$ \\
\hline $30 \mathrm{~min}$ post-GnRH & $141.2 \pm 28.1$ & $37.7 \pm 5.5^{*}$ & $31.2 \pm 3.8^{*}$ & $88.5 \pm 33.1$ & $20.7 \pm 5.0 *$ & $19.5 \pm 2.5 *$ \\
\hline Change & $51.9 \pm 12.4$ & $18.7 \pm 4.4 *$ & $14.8 \pm 3.8^{*}$ & $17.8 \pm 8.1$ & $9.9 \pm 3.3$ & $6.7 \pm 1.3$ \\
\hline 120 min post-GnRH & $116.6 \pm 22.7$ & $25.5 \pm 2.2 *$ & $20.3 \pm 2.1 *$ & $71.1 \pm 34.4$ & $12.7 \pm 2.4 *$ & $15.8 \pm 1.8^{*}$ \\
\hline Change & $27.3 \pm 7.3$ & $6.4 \pm 1.8^{*}$ & $3.8 \pm 1.2 *$ & $0.4 \pm 2.5$ & $1.9 \pm 0.5$ & $3.0 \pm 0.6$ \\
\hline \multicolumn{7}{|l|}{ Serum LH (ng/ml) } \\
\hline Pre-GnRH & $0.50 \pm 0.30$ & $0.14 \pm 0.05$ & $0.30 \pm 0.12$ & $0.08 \pm 0.02$ & $0.03 \pm 0.01$ & $0.05 \pm 0.02$ \\
\hline 30 min post-GnRH & $6.39 \pm 3.05$ & $7.62 \pm 1.06$ & $9.37 \pm 1.38$ & $5.49 \pm 1.33$ & $4.40 \pm 0.97$ & $5.42 \pm 0.64$ \\
\hline Change & $5.89 \pm 3.15$ & $7.49 \pm 1.05$ & $9.07 \pm 1.42$ & $5.41 \pm 1.34$ & $4.37 \pm 0.98$ & $5.36 \pm 0.63$ \\
\hline 120 min post-GnRH & $0.16 \pm 0.03$ & $0.38 \pm 0.05 *$ & $0.31 \pm 0.04$ & $0.35 \pm 0.17$ & $0.14 \pm 0.02$ & $0.44 \pm 0.12$ \\
\hline Change & $-0.34 \pm 0.30$ & $0.24 \pm 0.08$ & $0.01 \pm 0.14$ & $0.26 \pm 0.18$ & $0.10 \pm 0.03$ & $0.39 \pm 0.12$ \\
\hline \multicolumn{7}{|c|}{ Serum testosterone $(\mathrm{ng} / \mathrm{ml})$} \\
\hline Pre-GnRH & $1.3 \pm 0.9$ & $3.4 \pm 1.0$ & $2.2 \pm 0.7$ & $5.8 \pm 1.5$ & $2.5 \pm 1.0$ & $5.6 \pm 2.3$ \\
\hline $30 \mathrm{~min}$ post-GnRH & $12.9 \pm 1.6$ & $5.7 \pm 0.5 *$ & $5.8 \pm 0.6 *$ & $18.1 \pm 6.4$ & $12.2 \pm 0.8$ & $13.0 \pm 0.8$ \\
\hline Change & $11.7 \pm 1.5$ & $2.2 \pm 0.9 *$ & $3.8 \pm 0.7 *$ & $12.3 \pm 7.4$ & $9.7 \pm 1.2$ & $7.3 \pm 2.2$ \\
\hline 120 min post-GnRH & $14.1 \pm 1.8$ & $8.6 \pm 0.8^{*}$ & $8.6 \pm 0.8^{*}$ & $15.1 \pm 1.6$ & $8.9 \pm 0.9 *$ & $10.3 \pm 1.0 *$ \\
\hline Change & $12.8 \pm 2.0$ & $5.2 \pm 0.8^{*}$ & $6.5 \pm 1.0 *$ & $9.3 \pm 2.6$ & $6.4 \pm 1.5$ & $4.8 \pm 2.5$ \\
\hline
\end{tabular}

Values represent mean \pm S.E.M. Within a row, values with an asterisk are different from control $(P<0.05)$ using ANOVA and Tukey-Kramer posthoc test.

third $(P>0.05)$ in both vinclozolin groups compared with the control group (Table 4). Predominant morphological defects in sperm from vinclozolin-exposed rabbits involved shape and non-homogeneity of the nucleus or shape and features of the acrosome. Approximately $25 \%$ of sperm were affected by one or both defects in vinclozolinexposed rabbits vs. $\sim 5 \%$ in control rabbits.

At a light microscopic level, these defects included nuclear aberrations resulting in misshaped heads (Figure 1a) and conjoined heads sharing a common abnormal acrosome (Figure 1b). Abnormal acrosomes were dysplastic and were characterized by a cystic or knobbed appearance. Occasionally, clusters of such abnormal sperm had been exfoliated along with Sertoli cell remnants (Figure 1c). At an electron microscopic level, these lesions first were evidenced in spermatids entering the acrosome phase of spermiogenesis, with abnormal spreading of the acrosomic vesicle (Figure 2a) or sometimes acrosomal invasion of the nucleus (Figure 2b). As chromatin condensed and the sperm head elongated during the nuclear phase of spermiogenesis, the dysplastic acrosomal vesicle became entrapped in the nucleus thereby resulting in vesiculation, nuclear invaginations, and craters (Figure 2c).

Table 4 Seminal parameters in 24-week-old rabbits developmentally exposed to vinclozolin.

\begin{tabular}{|c|c|c|c|}
\hline & Control & Low Vinclozolin & High Vinclozolin \\
\hline$n$ & 8 & 7 & 10 \\
\hline $\begin{array}{l}\text { Tissue homogenates } \\
\text { Daily sperm production }\left(10^{6} / \mathrm{g} \text { testis) }\right. \\
\text { Caput-corpus epididymal sperm reserve }\left(10^{6}\right) \\
\text { Cauda epididymal sperm reserve }\left(10^{6}\right)\end{array}$ & $\begin{array}{c}24.6 \pm 1.2 \\
107.6 \pm 9.1 \\
452.6 \pm 66.2\end{array}$ & $\begin{array}{c}23.8 \pm 1.2 \\
113.6 \pm 18.9 \\
328.3 \pm 39.8\end{array}$ & $\begin{array}{c}24.0 \pm 0.7 \\
101.9 \pm 10.8 \\
396.6 \pm 33.4\end{array}$ \\
\hline $\begin{array}{l}\text { Semen parameters } \\
\text { Ejaculate volume }(\mathrm{ml}) \\
\text { Sperm concentration }\left(10^{6} / \mathrm{ml}\right) \\
\text { Total sperm/ejaculate }\left(10^{6}\right)\end{array}$ & $\begin{array}{r}0.32 \pm 0.02(48) \\
400.8 \pm 30.5(46) \\
129.5 \pm 12.1(46)\end{array}$ & $\begin{array}{r}0.37 \pm 0.03(29) \\
441.2 \pm 26.5(29) \\
160.0 \pm 14.8(29)\end{array}$ & $\begin{array}{r}0.34 \pm 0.02(54) \\
341.2 \pm 20.3(52) \\
116.7 \pm 10.9(52)\end{array}$ \\
\hline $\begin{array}{l}\text { Sperm morphology } \\
\text { Morphologically normal sperm (\%) } \\
\text { Acrosome defects (\%) } \\
\text { Nuclear defects }(\%)\end{array}$ & $\begin{array}{l}79.6 \pm 1.4(46) \\
4.94 \pm 0.76(46) \\
6.00 \pm 0.85(46)\end{array}$ & $\begin{aligned} 53.1 & \pm 3.4(29) * \\
25.69 & \pm 2.48(29) * \\
22.60 & \pm 1.97(29) *\end{aligned}$ & $\begin{aligned} 52.3 & \pm 1.6(51) * \\
24.87 & \pm 1.27(51) * \\
24.28 & \pm 1.19(51) *\end{aligned}$ \\
\hline
\end{tabular}

Values represent mean \pm S.E.M. Within a column, values with an asterisk are different from control $(P<0.05)$ using ANOVA and Tukey-Kramer posthoc test. Numbers in parentheses are total number of samples counted. 

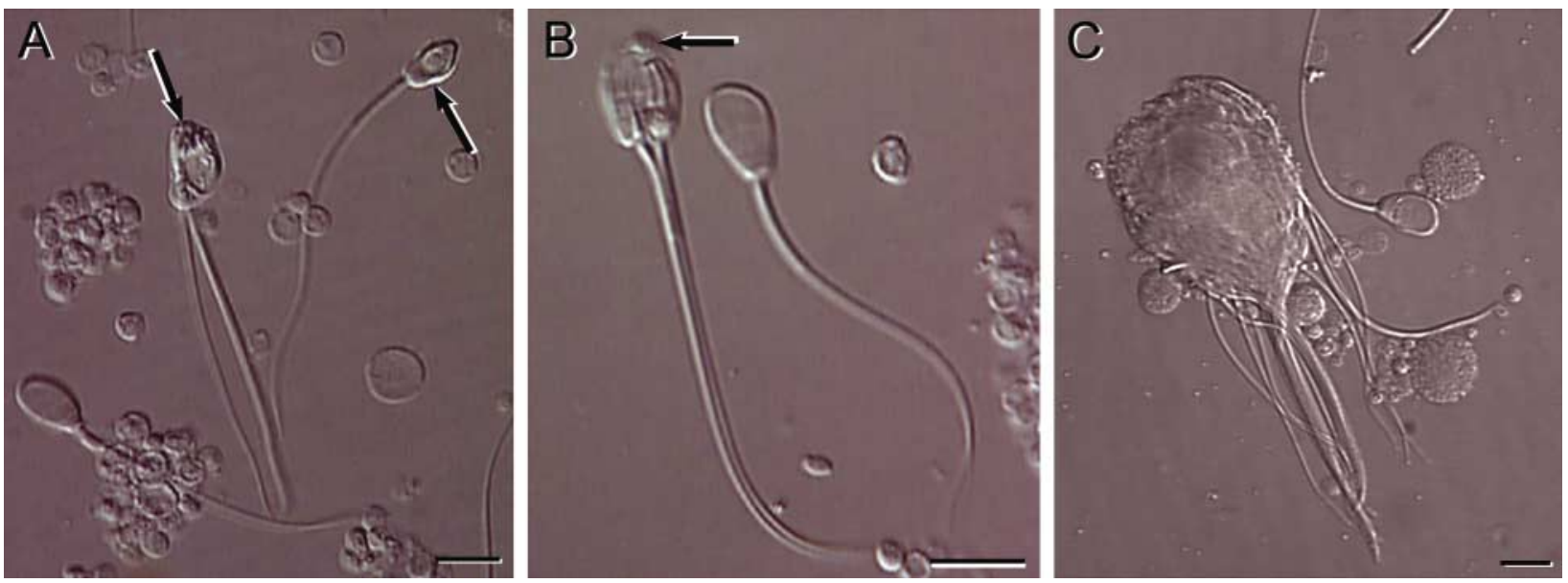

Figure 1 Differential interference contrast micrographs of ejaculated sperm from 24-week-old rabbits exposed to vinclozolin in utero and lactationally during the first 4 weeks of life. (A) Malformed sperm heads. Note craters and invaginations in the nuclei (arrows). Several of these malformations involved both acrosomes and nuclei. (B) Two conjoined sperm with malformed heads. Note presence of a dysplastic knobbed/cystic acrosome (arrow) shared between two sperm heads. (C) A cluster of sperm embedded in a Sertoli cell remnant indicating seminiferous epithelial degeneration and denudation. Scale bars $=10 \mu \mathrm{m}$.

\section{Histopathology of testis}

Histopathological changes in testes representing grades 1 and 2 were found in all groups of rabbits (Table 5), including controls; the incidence was higher $(P<0.05)$ for grade 1 lesions in low dose vinclozolin group and for grade 2 lesions in high dose group. The higher incidence of these lesions in vinclozolin-exposed rabbits was mirrored by fewer $(P<0.05)$ normal (grade 0$)$ seminiferous tubules. Examples are in Figure $3 a$ and $3 b$. A few grade 3 or 4 tubules also were found in high vinclozolin males as well as in the control group. Lesions in vinclozolin rabbits were characterized by formation of 'multinucleated giant cells', in reality a syncytium of spherical spermatids, members of a cohort undergoing pyknotic changes (Figure 3b). Ultimately, such cells are exfoliated leaving fluid-filled spaces within the Sertoli cells. The desquamated cells are transported through the excurrent ducts (Figure $3 \mathrm{~d}$ ) and can appear in ejaculated semen. Except for these spermatidal syncytia and abnormal spermatids, no atypical germ cells were observed. Collectively, lesions in the seminiferous epithelium were reflected in higher $(P<0.05)$ DGEL for vinclozolin-exposed males (Table 5).
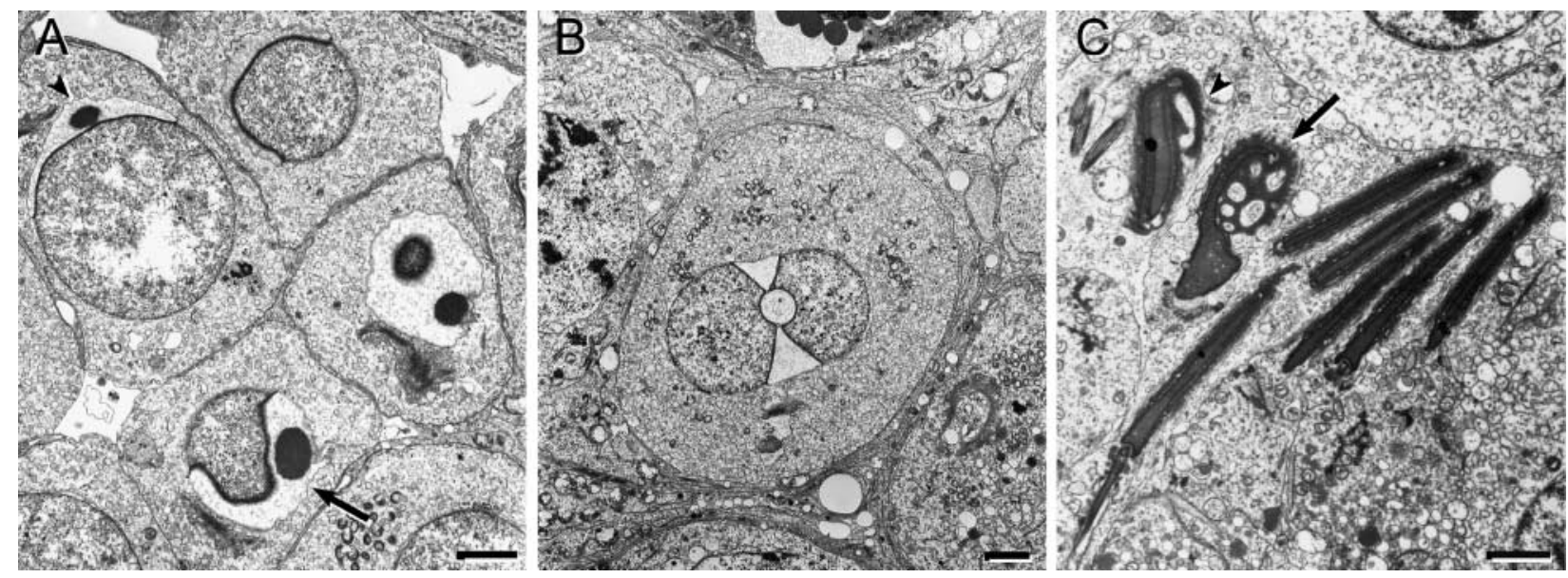

Figure 2 Transmission electron micrographs of testicular sections from 24-week-old rabbits exposed to vinclozolin in utero and lactationally during the first 4 weeks of life. (A) Spherical spermatids in the acrosome phase of spermiogenesis. In the upper left of the micrograph, note a normal acrosomic vesicle with a granule (arrow head) spreading the acrosomal cap uniformly around the nucleus. In the lower right, note irregular spread of the acrosomal cap (arrow) distorting the spermatid nucleus. (B) A dysplastic acrosomal vesicle invading the spermatid nucleus. (C) Condensing spermatid nuclei each with a dysplastic acrosome (arrow head), invagination of acrosomal matrix into nucleus, and inclusions of Sertoli cell processes in the nucleus (arrow). Note cystic/knobbed acrosome (arrow head) with excess acrosomal material and the nuclear inclusions resembling cytoplasmic constituents of a Sertoli cell (arrow). Scale bars $=2 \mu \mathrm{m}$. 
Table 5 Histopathological changes in the seminiferous epithelium in 24-week-old rabbits developmentally exposed to vinclozolin.

\begin{tabular}{|c|c|c|c|c|c|c|c|c|}
\hline \multirow[b]{2}{*}{ Treatment } & \multirow[b]{2}{*}{$n$} & \multicolumn{6}{|c|}{ Percentage of seminiferous tubules graded as: } & \multirow[b]{2}{*}{ Degree of germinal epithelial loss } \\
\hline & & 0 & 1 & 2 & 3 & 4 & $5-7$ & \\
\hline Control & 8 & $87.4 \pm 1.5$ & $6.8 \pm 1.2$ & $4.6 \pm 0.9$ & $1.00 \pm 0.50$ & $0.25 \pm 0.25$ & - & $5.0 \pm 1.0$ \\
\hline Low vinclozolin & 7 & $69.9 \pm 2.3 *$ & $19.4 \pm 2.8^{*}$ & $10.7 \pm 2.4$ & - & - & - & $10.2 \pm 0.9 *$ \\
\hline High vinclozolin & 10 & $77.4 \pm 2.2 *$ & $9.2 \pm 0.9$ & $13.0 \pm 2.0 *$ & $0.10 \pm 0.10$ & $0.30 \pm 0.21$ & - & $9.2 \pm 1.0 *$ \\
\hline
\end{tabular}

Values represent mean \pm S.E.M. Within a column, values with an asterisk are different from control $(P<0.05)$ using ANOVA and Tukey-Kramer posthoc test.

\section{Discussion}

At the doses tested, developmental exposure to vinclozolin did not affect testicular descent, but impaired sexual function, FSH secretion, and spermiogenesis. Although we did not measure concentrations of vinclozolin and its metabolites in our rabbits, we assume that M1 and M2 were present in circulation during critical periods of sexual differentiation (in fetuses via transplacental exposure) and post-natal development (in pups via lactational exposure). This assumption was based on a study using Dutch-Belted rabbits (Moorman et al. 2000) in which parent compound and its metabolites: a) peaked in blood at $10 \mathrm{~h}$ following a single dermal application of $100 \mathrm{mg}$ of vinclozolin/kg (in $100 \mu$ l dimethyl sulphoxide); and b) were found in blood up to 2 months after cessation of similar daily dermal application for 2 months (5 days/week).
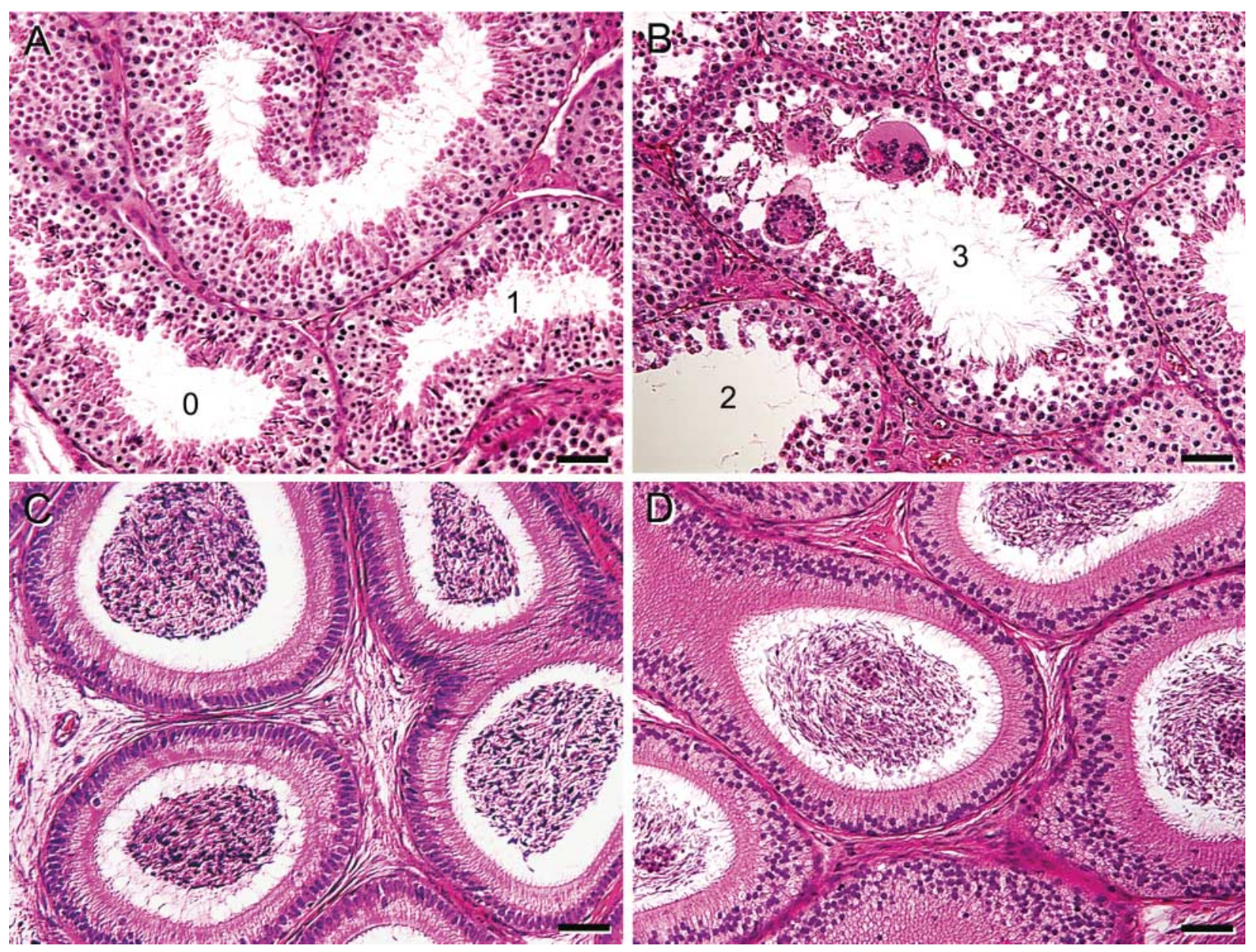

Figure 3 Photomicrographs of testicular and epididymal sections from 24-week-old control and vinclozolin-exposed rabbits. (A) Seminiferous tubules in a control testis showing normal seminiferous epithelium (grade 0) and isolated, focal vacuolation of seminiferous epithelium (grade 1). (B) Seminiferous tubules in a high-dose vinclozolin rabbit showing moderate (grade 2) and extensive vacuolation (grade 3) in seminiferous epithelium containing pyknotic spherical spermatid syncytia (multinucleated giant cells). (C) Corpus epididymidis of a control rabbit showing normal luminal contents. (D) Corpus epididymidis of a high-vinclozolin rabbit with luminal sperm containing aggregates of exfoliated immature germ cells. Numbers within the tubules designate grades of pathological change. Hematoxylin and eosin staining. Scale bars $=50 \mu \mathrm{m}$. 
Regardless of concentrations of vinclozolin, M1 or M2 at target tissues of our rabbits, neither dose of vinclozolin affected testicular descent. This probably means that the high dose in this study did not provide sufficient antiandrogenic action to interfere with testicular descent. We rejected the possibilities that exposure to vinclozolin did not encompass a critical window or that anti-androgens are irrelevant. Vulnerability of male rabbit fetuses to anti-androgens during the exposure window used in the current study is logical because it encompasses androgendependent differentiation. Interstitial cells (future Leydig cells) of the fetal rabbit testis remain undifferentiated until GD 17, and perhaps begin hormone secretion near GD 20 (Bjerregaard et al. 1974, Gondos 1974, Catt et al. 1975). Indifferent supporting cells (future Sertoli cells) start to undergo morphological and biochemical changes indicative of endocrine activity approximately by GD 20 (Gondos et al. 1973, Gondos 1974). Secretions of both cell types are involved in differentiation of the reproductive system (Bloch et al. 1971, Klonisch et al. 2004). In rabbits, testosterone concentration in fetal blood/tissue remains high until birth, when it drops and remains low until PND 40 (Veyssiere et al. 1976, Berger et al. 1982).

In respect to impact of anti-androgens, testicular descent was blocked in male rabbits exposed during a similar window of sexual differentiation to known anti-androgens (i.e., $p, p^{\prime}$-DDE (1,1-dichloro-2,2-bis(p-chlorophenyl)ethylene) or flutamide; Veeramachaneni 2006). Also, for rats, Gray et al. (1994) reported suprainguinal ectopic testes in males born to dams exposed to $100 \mathrm{mg}$ vinclozolin/kg/day between GD 14 and PND 3. However, our high dose was only $72 \mathrm{mg} / \mathrm{kg} /$ day.

Sexual behavior and mating ability of adult males evaluated 20 weeks after cessation of exposure to low dose vinclozolin were aberrant in the present study, probably due to prenatal exposure. Historic data for our laboratory (1991-2002, not including this study) show that none of 92 control males failed to mount and ejaculate in similar episodes. However, 2 of 7 low-dose vinclozolin males totally lacked sexual interest and failed to display penile erection, and 2 high-dose males failed to achieve an erection and copulate at least once (Table 2). Similar impairment of mating ability apparently was not encountered in rabbits exposed to vinclozolin between 3 and 5 months of age $(100 \mathrm{mg}$ vinclozolin/kg/day in $100 \mu \mathrm{l}$ dimethyl sulphoxide dermal application, 5 days/week; Moorman et al. 2000) as no impediment was reported in collection of multiple ejaculates weekly over a 5 week period beginning at 6 months of age. Further support that early development is when the effect on behavior was manifested comes from observations that male rabbits exposed developmentally to chemical pollutants common in drinking water (Veeramachaneni et al. 2001) or a water disinfection by-product dibromoacetic acid (Veeramachaneni et al. 2000) manifested aberrant sexual behavior and function.

Studies with rats reveal that dose-response relationships are not equivalent among endpoints affected by exposure to vinclozolin (NTP/NIEHS 2001). Some endpoints demonstrate threshold effects, with alteration only at high doses, whereas other endpoints are linear to the lowest dose tested. Clearly, further studies with multiple endpoints are warranted to delineate low-dose effects of chemicals such as vinclozolin.

It is possible that vinclozolin disrupts differentiation of brain regions important for regulating male sexual behaviors. Across a large number of vertebrate species, one particularly important region is the preoptic area and anterior hypothalamus (POA/AH) - a region well-known for sex differences in brain structure and function (reviewed by Tobet \& Fox 1992). While estrogens are known to bind to receptors in this region of the rabbit brain (Caba et al. 2003), male/female differences and their dependence on developmental exposure to estrogens or androgens have not been examined. Emerging data from our laboratory reveal that the rabbit $\mathrm{POA} / \mathrm{AH}$ is sexually dimorphic, and that vinclozolin seems to disrupt organization of a specific, sexually dimorphic region that is known to be critical in male sexual behavior. Exposure to vinclozolin $(10 \mathrm{mg} / \mathrm{kg} /$ day administered orally to dams from GD15 to PND 28) significantly increased expression of calbindin in the ventral POA/AH (a biomarker for sexual differences in this area of hypothalamus) and significantly decreased $\mathrm{GnRH}$ neuron number selectively in the region of organum vasculosum of the lamina terminalis (Bisenius et al. 2005). In rodents, the role of estrogenic metabolites of testosterone is pre-eminent in most aspects of brain sexual differentiation. In rabbits, apparently, an anti-androgenic metabolite of vinclozolin (possibly M2), which has a very low affinity for estradiol receptors in rats (Kelce et al. 1994), alters the POA/AH (Bisenius et al. 2005) and disrupts sexual behavior of male rabbits (Table 2). Hence, rabbits should be a useful model to study influences of exogenous chemicals during early neural development, with implications for humans. Both androgens and anti-androgens should be compared, because in nonhuman primates developmental exposure to androgens masculinizes sexually dimorphic regions of the brain and enhances male-typical expression of mounting behavior in adults (Pomerantz et al. 1985, 1986, Thornton \& Goy 1986).

We assume erectile dysfunction in some vinclozolinexposed rabbits is not from insufficient testosterone or delayed puberty; serum testosterone was not deficient (Table 3) and quantitatively spermatogenesis was normal (Table 4). A complete lack of sexual interest in 2 low-dose vinclozolin rabbits points to permanent disruption of elements of the central nervous system that control sexual behavior and function. An alternate explanation for the behavioral defects could be that vinclozolin metabolites interfere with activin receptor II signaling in the POA. Knockout mice lacking activin receptor II have reduced levels of serum FSH (Kumar et al. 2001) and display various deficiencies in male sexual behavior (Ma et al. 2005). Reduction in available FSH per se does not explain 
deficits in sexual behavior because no such anomaly has been observed in FSH or FSH-receptor knockout male mice (Kumar 2005). Future studies should evaluate if activin II signaling in the POA of vinclozolin-treated rabbits is affected.

There is evidence that vinclozolin affects neuronal development or erectile function in rodents and birds. Prenatal exposure of rats to vinclozolin affects play behavior, a sexually dimorphic trait. Hotchkiss et al. (2003) reported a decrease in play behavior in rats following exposure to $200 \mathrm{mg}$ vinclozolin/kg body weight/day on PND 2 and 3, whereas Colbert et al. (2005) reported an increase following daily exposure to $12 \mathrm{mg}$ vinclozolin/kg body weight/ day between GD 14 and PND 3. Erectile function was found to be significantly reduced in the latter study. Vinclozolin alters $\mathrm{GnRH}$ secretion in male Japanese quail hatchlings and impairs sexual behavior (McGary et al. 2001).

Apparently, developmental exposure of rabbit fetuses/ pups to vinclozolin had a permanent effect on the hypothalamic-pituitary-gonadal axis. Surprisingly, impact on serum concentrations of FSH was greater than impact on basal LH or discharge of $\mathrm{LH}$ in response to $\mathrm{GnRH}$ (Table 3). At both 12 and 24 weeks of age, mean baseline concentrations of $\mathrm{LH}$ or testosterone in vinclozolinexposed rabbits were not significantly different from those of control rabbits. However, compared with controls, the response of Leydig cells to a $\mathrm{GnRH}$-induced increase in blood LH was significantly lower in vinclozolin-exposed rabbits at 12 weeks of age. The presumed impairment of full potential of Leydig cell function, evidenced at 12 weeks, apparently was masked at 24 weeks of age by testis growth or evolving function.

Remarkably, basal concentration of FSH as well as pituitary secretion/discharge of FSH after exogenous GnRH were significantly lower in vinclozolin-exposed rabbits than in controls, at both 12 and 24 weeks of age. This diminution in $\mathrm{FSH}$ secretion was evident at 6 weeks of age. Perhaps the regulatory mechanism by which androgen stimulates $\mathrm{FSH} \beta$ gene expression in immortalized rat gonadotropes (Spady et al. 2004), if operational in rabbits, was permanently disrupted by exposure to vinclozolin during development. Regardless, it is known that a severe deficiency in FSH available to Sertoli cells adversely affects their function and results in aberrant spermiogenesis (reviewed by Sharpe 1994).

Formation of morphologically normal sperm requires complex interactions of Sertoli cells and developing spermatids, with the latter using mRNA and proteins primarily produced while these cells were precursor spermatocytes. Given that sperm with acrosomal-nuclear defects were ejaculated 20 weeks after cessation of vinclozolin exposure (spermiation of these cells occurred 10-14 days earlier; it takes 49 days to develop from a stem spermatogonium to spermiation; Amann 1982), it is likely that a permanent epigenetic change had been induced in stemspermatogonia and/or Sertoli cells. Within a given testis some, but not all, of a specific cell type apparently was permanently altered at doses of vinclozolin administered. Eventually, cells displaying these lesions accumulate to provide aberrations evidenced in seminiferous tubules of vinclozolin-exposed rabbits at 24 weeks. The percentage of histologically normal (grade 0 ) seminiferous tubules was reduced in vinclozolin-exposed rabbits.

Sperm nuclear-acrosomal defects identical to those observed in this study were found for rabbits exposed to chemical contaminants common in drinking water (Veeramachaneni et al. 2001); for rabbits (unpublished observations) and rats (Linder et al. 1997) exposed to dibromoacetic acid; and for subfertile/infertile stallions (Veeramachaneni \& Sawyer 1996). Perhaps these horses had been unwittingly exposed to pollutants similar to those we tested in rabbits. With several stallions, nuclearacrosomal defects were detected in multiple evaluations over 3-4 years. It is not known if similar defects in bull sperm are inducible, or result from environmental agents, but some acrosomal defects are passed from generation to generation (Saacke et al. 1968). Collectively, these observations indicate that acrosomal-nuclear defects of sperm are inducible and perpetuating.

Epigenetic effects on testicular function and spermatogenesis is a new area, and there are more questions than answers/concepts. Clearly vinclozolin or its metabolites can have an epigenetic effect on rats transmitted through sperm (Anway et al. 2005), although other affected cell types were not disclosed. At this time, we interpret our data as evidence that reprogramming of the exposed generation involves sexually dimorphic regions of the brain; Leydig cells, Sertoli cells, and stem spermatogonia in the testes. It is unclear if reprogramming of the germ cells or Sertoli cells by vinclozolin or metabolites was responsible for nuclear-acrosomal defects of ejaculated sperm from our rabbits or if the induced sperm defects can be transmitted to the next generation. Perhaps these adverse effects at disparate sites are mediated by as yet unravelled actions of vinclozolin, or metabolites, independent of antagonistic action at the androgen receptor level.

Increasing incidence of human testicular dysgenesis and deteriorating seminal quality have been postulated to be linked to environmental pollutants (Skakkebaek et al. 2001). Subtle, yet lasting lesions such as acrosomal dysgenesis and pronounced aberrations in sexual function, as observed in this study, are only beginning to be experimentally associated with specific chemicals (e.g., Veeramachaneni et al. 2000, 2001). Epigenetic disruptive actions of vinclozolin on fertility of male rats are transmitted over generations (Anway et al. 2005). In most natural situations, human or animal exposures do not involve a single chemical but a multitude of agents. In these situations, chemicals that produce similar end results may act in a cumulative manner either synergistically or additively. In this context, vinclozolin, with an estimated average exposure in children at $0.167 \mathrm{mg} / \mathrm{kg}$ body weight/day (USEPA 2000), could be an important 
component within the mix of many anti-androgenic pollutants that impinge upon male fetuses and children to impact their reproductive health years later.

\section{Acknowledgements}

We are grateful to $\mathrm{Dr} \mathrm{K}$ Bodensteiner, C LeCheminant, C Moeller, G Sammonds, and J Yamane for technical assistance. We thank Drs TR Kumar and SA Tobet for reviewing the manuscript. This study was supported by USEPA STAR grant R826131 and NIH-NIEHS grant R21ES013810. The authors declare that there is no conflict of interest that would prejudice the impartiality of this scientific work.

\section{References}

Amann RP 1982 Use of animal models for detecting specific alterations in reproduction. Fundamental and Applied Toxicology 2 13-26.

Amann RP, Kavanaugh JF, Griel LC Jr \& Voglmayr JK 1974 Sperm production of Holstein bulls determined from testicular spermatid reserves after cannulation of rete testis or vas deferens and by daily ejaculation. Journal of Dairy Science 57 93-99.

Amann RP \& Lambiase JT 1969 The male rabbit III. Determination of daily sperm production by means of testicular homogenates. Journal of Animal Science 28 369-374.

Anway DA, Cupp AS, Uzumcu M \& Skinner MK 2005 Epigenetic transgenerational actions of endocrine disruptors and male fertility. Science 308 1466-1469.

Berger M, Jean-Faucher C, de Turckheim M, Veyssiere G, Blanc MR, Poirier JC \& Jean C 1982 Testosterone luteinizing hormone (LH) and follicle stimulating hormone (FSH) in plasma of rabbit from birth to adulthood. Correlation with sexual and behavioral development. Acta Endocrinologica (Copenhagen) 99 459-465.

Berndtson WE, Pickett BW \& Nett TM 1974 Reproductive physiology of the stallion IV Seasonal changes in the testosterone concentration of peripheral plasma. Journal of Reproduction and Fertility 39 115-118.

Bisenius E, Sammonds G, Veeramachaneni DNR \& Tobet S 2005 Sex differences and hormone influences on the development of the rabbit brain. In Proceedings of 35th Annual Meeting of Society for Neuroscience, Abstract, Washington, DC, USA.

Bjerregaard P, Bro-rasmussen F \& Reumert T 1974 Ultrastructural development of fetal rabbit testis. Zeitschrift fur Zellforsch und Mikroskopische Anatomie 147 401-413.

Bloch E, Lew M \& Klein M 1971 Studies on the inhibition of fetal androgen formation. Inhibition of testosterone synthesis in rat and rabbit fetal testes with observations on reproductive tract development. Endocrinology 89 16-31.

Bredderman PJ, Foote RH \& Yassen AM 1964 An improved artificial vagina for collecting rabbit semen. Journal of Reproduction and Fertility 7 401-403.

Caba M, Beyer C, Gonzalez-Mariscal G \& Morrell JI 2003 Immunocytochemical detection of estrogen receptor-alpha in the female rabbit forebrain: topography and regulation by estradiol. Neuroendocrinology 77 208-222.

Catt KJ, Dufau ML, Neaves WB, Walsh PC \& Wilson JD 1975 LHhCG receptors and testosterone content during differentiation of the testis in the rabbit embryo. Endocrinology 97 1157-1165.

Colbert NKW, Pelletier NC, Cote JM, Concannon JB, Jurdak NA, Minott SB \& Markowski VP 2005 Perinatal exposure to low levels of the environmental antiandrogen vinclozolin alters sex-differentiated social play and sexual behaviors in the rat. Environmental Health Perspectives 113 700-707.
Gondos B 1974 Differentiation and growth of cells in the gonads. In Differentiation and Growth of Vertebrate Tissues, pp 169-208. Ed. G Goldspink. London: Chapman and Hall.

Gondos B, Renston RH \& Conner LA 1973 Ultrastructure of germ cells and Sertoli cells in the postnatal rabbit testis. American Journal of Anatomy 136 427-440.

Gondos B, Renston RH \& Goldstein DA 1975 Postnatal differentiation of Leydig cells in the rabbit testis. American Journal of Anatomy 145 167-182.

Gray LE Jr, Ostby JS \& Kelce WR 1994 Developmental effects of an environmental antiandrogen: the fungicide vinclozolin alters sex differentiation of the male rat. Toxicology and Applied Pharmacology 129 46-52.

Gray LE Jr, Ostby J, Furr J, Wolf CJ, Lambright C, Parks L, Veeramachaneni DN, Wilson V, Price M, Hotchkiss A, Orlando E \& Guillette L 2001 Effects of environmental antiandrogens on reproductive development in experimental animals. Human Reproduction Update 7 248-264.

Hancock JL 1957 The morphology of boar spermatozoa. Journal of Royal Microscopy Society 76 84-97.

Higuchi TT, Palmer JS, Gray LE Jr \& Veeramachaneni DNR 2003 Effects of dibutyl phthalate in male rabbits following in utero adolescent or postpubertal exposure. Toxicological Sciences $\mathbf{7 2}$ $301-313$.

Hotchkiss AK, Ostby JS, Vandenbergh JG \& Gray LE Jr 2003 An environmental antiandrogen vinclozolin alters the organization of play behavior. Physiology and Behavior 79 151-156.

Kelce WR, Monosson E, Gamcsik MP, Laws SC \& Gray LE Jr 1994 Environmental hormone disruptors: Evidence that vinclozolin developmental toxicity is mediated by antiandrogenic metabolites. Toxicology and Applied Pharmacology 126 276-285.

Klonisch T, Fowler PA \& Hombach-Klonisch S 2004 Molecular and genetic regulation of testicular descent and external genitalia development. Developmental Biology 270 1-18.

Kumar TR 2005 What have we learned about gonadotropin function from gonadotropin subunit and receptor knockout mice? Reproduction 130 293-302.

Kumar TR, Varani S, Wreford NG, Telfer NM, de Kretser DM \& Matzuk MM 2001 Male reproductive phenotypes in double mutant mice lacking both FSHbeta and activin receptor IIA. Endocrinology 142 3512-3518.

Laumann E, Paik A \& Rosen RC 1999 Sexual dysfunction in the United States Prevalence and Predictors. Journal of the American Medical Association 281 537-544.

Linder RE, Klinefelter GR, Strader LF, Veeramachaneni DNR Roberts NL \& Suarez JD 1997 Histopathologic changes in the testis of rats exposed to dibromoacetic acid. Reproductive Toxicology 11 47-56.

Ma X, Reyna A, Mani SK, Matzuk MM \& Kumar TR 2005 Impaired Male Sexual Behavior in Activin Receptor Type II Knockout Mice. Biology of Reproduction 73 1182-1190.

McGary S, Henry PF \& Ottinger MA 2001 Impact of vinclozolin on reproductive behavior and endocrinology in Japanese quail (Coturnix coturnix japonica). Environmental Toxicology and Chemistry 20 2487-2493.

Moorman WJ, Cheever KL, Skaggs SR, Clark JC, Turner TW, Marlow KL \& Schrader SM 2000 Male adolescent exposure to endocrinedisrupting pesticides: vinclozolin exposure in peripubertal rabbits. Andrologia 32 285-293.

NRC 1993 Pesticidies in the diets of infants and children. National Research Council, Washington DC: National Academy Press.

NTP/NIEHS 2001 National Toxicology Program's Report of the Endocrine Disruprtors Low-Dose Peer Review. Availible: http:// ntp-server.niehs.nih.gov/htdocs.liason/LowDoseWebPage.html.

Oliva A, Giami A \& Multigner L 2002 Environmental agents and erectile dysfunction: a study in a consulting population. Journal of Andrology 23 546-550.

Pomerantz SM, Roy MM, Thornton JE \& Goy RW 1985 Expression of adult female patterns of sexual behavior by male female and 
pseudohermaphroditic female rhesus monkeys. Biology of Reproduction 33 878-889.

Pomerantz SM, Goy RW \& Roy MM 1986 Expression of male-typical behavior in adult female pseudohermaphroditic rhesus: comparisons with normal males and neonatally gonadectomized males and females. Hormones and Behavior 20 483-500.

Pau K-YF, Orstead KM, Hess DL \& Spies HG 1986 Feedback effects of ovarian steroids on the hypothalamic-hypophyseal axis in the rabbit. Biology of Reproduction 35 1009-1023.

Saacke RG, Amann RP \& Marshall CE 1968 Acrosomal cap abnormalities of sperm from subfertile bulls. Journal of Animal Science $271391-1400$.

Sharpe RM 1994 Regulation of spermatogenesis. In The Physiology of Reproduction, 2nd edn, pp 1363-1434. Eds E Knobil \& JD Neill. New York: Raven Press.

Spady TJ, Shayya R, Thackray VG, Ehrensberger L, Bailey JS \& Mellon PM 2004 Androgen regulates follicle-stimulating hormone beta gene expression in an activin-dependent manner in immortalized gonadotropes. Molecular Endocrinology 18 925-940.

Skakkebaek NE, Rajpert-De Meyts E \& Main KM 2001 Testicular dygenesis syndrome: an increasingly common developmental disorder with environmental aspects. Human Reproduction $\mathbf{1 6}$ 972-978.

Thornton J \& Goy RW 1986 Female-typical sexual behavior of rhesus and defeminization by androgens given prenatally. Hormones and Behavior 20 129-147.

Tobet S \& Fox T 1992 Sex differences in neuronal morphology influenced hormonally throughout life. In Sexual Differentiation, Vol 11 of Handbook of Behavioral Neurobiology, pp 41-83. Eds. AA Gerall, H Moltz, IL Ward, New York: Plenum Press.

Toppari J, Larsen J, Christiansen P, Giwercman A, Grandjean P, Gyillette LJ Jr, Jegou B, Jensen TK, Jouannet P, Keiding N, Leffers H, McLachlan JA, Meyer O, Muller J, Rajpert-De Meyts E, Scheike T, Sharpe R, Sumpter J \& Skakkebaek NE 1996 Male reproductive health and environmental xenoestrogens. Environmental Health Perspectives 104 (Supplement 4) 741-803.

US EPA 2000 In Vinclozolin Results of Revised Dietary Risk Assessment, http://www.epa.gov/pesticides/reregistration/ vinclozolin/deem2.pdf. U S Environmental Protection Agency, Washington DC.

Veeramachaneni DNR 2006 Germ cell atypia in undescended testes hinges on the aetiology of cryptorchidism but not the abdominal location per se. International Journal of Andrology 29 235-240.

Veeramachaneni DNR, Ott RS, Heath EH, McEntee K, Bolt DJ \& Hixon JE 1986 Pathophysiology of small testes in beef bulls: relationship between scrotal circumference histopathologic features of testes and epididymides seminal characteristics and endocrine profiles. American Journal of Veterinary Research 47 1988-1999.

Veeramachaneni DNR, Moeller CL, Pickett BW, Shiner KA \& Sawyer HR 1993 On processing and evaluation of equine seminal samples for cytopathology and fertility assessment: the utility of electron microscopy. Journal of Equine Veterinary Science 13 207-215.

Veeramachaneni DNR, Higuchi TT, Palmer JS \& Kane CM 2000 Dibromoacetic acid a disinfection by-product in water impairs sexual function and fertility in male rabbits. Biology of Reproduction 62 (Supplement 1) 24.

Veeramachaneni DNR, Palmer JS \& Amann RP 2001 Long-term effects on male reproduction of early exposure to common chemical contaminants in drinking water. Human Reproduction $\mathbf{1 6}$ 979-987.

Veeramachaneni DNR \& Sawyer HR 1996 Use of semen as biopsy material for assessment of health status of the stallion reproductive tract. Veterinary Clinics of North America: Equine Practice on Diagnostic Techniques and Assisted Reproductive Techniques 12 $101-110$

Veyssiere G, Berger M, Jean-Faucher C, De Turckheim M \& Jean C 1976 Levels of testosterone in the plasma, gonads and adrenals during fetal development of the rabbit. Endocrinology 99 1263-1268.

Received 17 November 2005

First decision 20 December 2005

Revised manuscript received 28 December 2005

Accepted 16 January 2006 